\title{
Evaluating the educational value of simulation games: Learners' perspective
}

\author{
Kholoud Mohsen $^{1 *}$, Shahpar Abdollahi ${ }^{2}$, Suha Omar ${ }^{3}$
}

\begin{abstract}
Simulation games (SG) offer great opportunities for students to learn and experience realworld business decisions in a risk-free learning environment. However, the impact of using SG on educational outcomes is not fully understood. Drawing on experiential learning theory, we develop a conceptual model to examine students' perceptions of the educational values generated from a SG adopted in a postgraduate program at a UK business school. The study gathered data from 120 students by using survey data and qualitative data from students' reflective reports. Results show that SG have positive impact on students' conceptual understanding, skills development and affective evaluation of their learning experience. The paper discusses the findings and its implications for educational practitioners and offers directions for future research.
\end{abstract}

Keywords: experiential learning, management education, strategic management, simulation games, students' experience, GLO-BUS

$1^{*}$ University of Essex, kmohsen@essex.ac.uk

2 University of Arts London, s.abdollahi@arts.ac.uk

3 De Montfort University, somar@dmu.ac.uk 


\section{Introduction}

One of the challenges facing management education (ME) is to develop students' critical thinking skills and enable students to link theory to practice (Lovelace, Eggers, \& Dyck, 2016). Business schools have been criticised for not adequately preparing graduates for the working environment (Pfeffer \& Fong, 2002). There is, in particular, increasing concern about the way business schools teach business strategy courses (Greiner, Bhambri, \& Cummings, 2003; Jarzabkowski, Giulietti, Oliveira, \& Amoo, 2013). Strategy courses have been criticised as being mainly theory based and overwhelming students with analytical tools that might lack relevance in today's ever changing environment (Bower, 2008). The debates about the relevance of ME to practice have resulted in the need to investigate effective approaches to teach strategy (Jarzabkowski et al., 2013).

Building on experiential learning (EL) theory, game-based learning literature argues that simulation games (SG) create a realistic representation of the professional environment students might encounter (Lovelace et al., 2016; Salas, Wildman, \& Piccolo, 2009). Consequently, SG provide students with valuable professional skills needed in today's workplace such as data analysis, strategic planning, decision making, problem solving and teamwork (Salas et al., 2009). EL has become an important approach in management education because of its premise that knowledge is created through the interface of theory and practice (Lovelace et al., 2016).

The fundamental value of SG in management education has been well established as they offer a safe, inexpensive and effective way of learning and enhance students' engagement (Lovelace et al., 2016). Despite the acknowledged importance of simulation-based learning, empirical studies that examine the effect of SG as a teaching tool in ME remain limited (Salas et al., 2009). Moreover, most of the existing literature in the evaluation of SG is largely descriptive (Leemkuil \& De Jong, 2012). Therefore, to advance this literature, it is paramount 
to evaluate the educational value of using SG from the learners' perspectives (Leemkuil \& De Jong, 2012; Lovelace et al., 2016).

This research contributes to the literature on the effectiveness of SG in enhancing students' ME in three respects. First, the article investigates the educational value generated from the use of a strategy-based SG. Second, the use of mixed method research design and data collected in three consecutive years provide a deeper insight into students' perspective of the effectiveness of SG in learning strategic management and enhancing learning experience. Third, based on lessons learned, practical guidance is provided on how to effectively use SG in ME and enhance students' learning.

The remainder of this article is organised as follows. The next section reviews experiential and game-based learning literature as the underpinning theoretical framework in developing the hypotheses. The third section describes the methodology of this study which is followed by detailed descriptions and interpretations of the data analysis. The article concludes with the 'discussion and conclusion' section which includes implications for theory, practice and research.

\section{Literature Review and Hypotheses Development}

\section{Experiential Learning Theory}

Experiential learning theory argues that learning is a process by which knowledge is created through the transformation of experience, which, in turn, is accomplished through the recognition and response to environmental and personal demands (Kolb \& Kolb, 2009). The process is represented by a learning cycle where learners create knowledge by encountering concrete experiences, processing them through reflective observation, refining and assimilating them through abstract conceptualization, and testing them through active experimentation. Kolb and Kolb (2005) further advanced EL theory by encompassing social 
and environmental factors as important determinants of learning. EL emerges when a participant cognitively, affectively, and behaviorally processes knowledge, skills, and/or attitudes in a learning situation characterised by a high level of active involvement (Kolb \& Kolb, 2009).

Research suggests that SG, by drawing on EL, offer many pedagogical benefits including cognitive, affective, and kinaesthetic engagement (Lovelace et al., 2016; Ranchhod, Gurău, Loukis, \& Trivedi, 2014). Furthermore, longitudinal studies (e.g., Wolfe \& Roberts, 1993) have reported significant relationships between students' business game performance and later career success. Moreover, studies on students' perceptions of learning in business simulated environments suggest that students value simulations and view them more positively than both lectures and case discussions (Lovelace et al., 2016). Drawing on the above literature, the following section hypothesises and examines how students' use of SG (experience generation) impacts educational outcomes such as conceptual understanding, skills development, and affective evaluation.

\section{Hypotheses Development}

The Impact of Experience Generation on Conceptual Understanding

Learning is a major factor that might result from good simulation performance (Wellington \& Faria, 1996). Strategy-based SG usually target students' analytical skills in making strategic decisions (Lovelace et al., 2016). Therefore, students can relate the concepts learned during the instructional part of the module to their strategic decisions in the game (Ranchhod et al., 2014). Applying the EL model, students experiment with a decision, reflect on it, generate a new abstract concept, generalise and repeat the cycle. Therefore, this process enables students to develop their understanding of strategic management concepts (Gosen \& Washbush, 2004; Zantow, Knowlton, \& Sharp, 2005). SG can provide a solid basis for 
learning as they help to increase comprehension of the complexity of organizations (Lovelace et al., 2016).

Hypothesis 1: The experience generation in the simulation game has a positive impact on students' conceptual understanding.

\section{The Impact of Experience Generation on Skills Development}

A major benefit of using SG is their potential in developing students' skills which is the primary objective of ME (Salas et al., 2009). Game-based learning literature argues that because SG create a realistic representation of the environment, students develop valuable skills such as data analysis, strategic planning, decision making, problem solving and teamwork (Ranchhod et al., 2014; Salas et al., 2009). The dynamic and competitive nature of strategy-based SG stimulates students' creativity, analytical reasoning and decision making skills (Gosen \& Washbush, 2004). SG are effective tools in ME because they allow for the development of management skills at a faster pace (Lovelace et al., 2016; Salas et al., 2009)

Hypothesis 2: The experience generation in the simulation game has a positive impact on students' skills development.

\section{The Impact of Experience Generation on Affective Evaluation}

Affective evaluation refers to the positive outcomes related to motivation, engagement and overall satisfaction of the simulation game experience (Ranchhod et al., 2014). SG offer great opportunities for students to learn and experience real-world issues, which induce actionable knowledge (Blood, 2006). Participating in the simulation requires students to work in teams which also encourages cooperative learning and enhances students' engagement and motivation (Kolb \& Kolb, 2005). Providing students with practice opportunities to apply their knowledge and skills in a system, that to a great extent resembles reality, has a positive 
impact on students' experience evaluation (Salas et al., 2009). Leemkuil and De Jong (2012) suggest that encouraging students to reflect on the consequences of their decisions in the simulation to improve their performance enhances students' learning experience.

Hypothesis 3: The experience generation in the simulation game has a positive impact on students' affective evaluation of their learning experience.

The Mediation Role of Conceptual Understanding and Skills Development

It is worth noting that there is literature that disputes the positive effects of using SG on students' learning experience. This literature argues that a poorly designed SG makes the learning experience a mere entertainment and not educational. For example, Kauneckis and Auer (2013) argue that a poorly designed SG could be considered a waste of valuable class time if it does not utilise research and creative problem-solving in a structured learning environment or link results to broader theoretical concepts. Examining educational values of using SG, Ranchhod et al. (2014) did not find statistical support for the positive impact of SG experience on students' affective evaluation. This study suggests that conceptual understanding and the skills developed from the simulation mediate the experience-affective evaluation relationship.

Hypothesis 4: Conceptual understanding mediates the relationships between experience generation and affective evaluation.

Hypothesis 5: Skills development mediates the relationships between experience generation and affective evaluation.

\section{Research Methodology}

This study utilises both qualitative and quantitative research methods to collect research data. Qualitative research addresses the complexity of the socio-cultural context within which 
the participants operate (Miles \& Huberman, 1994). Quantitative research was employed to test the conceptual model and the hypotheses. The use of mixed-method research was considered suitable for evaluating students' experience of using the simulation as it allows the study of different aspects of the experience (Creswell, 2009).

\section{Research Context}

The participants of this study are 120 postgraduate students who were enrolled in an international marketing strategy and planning module at a UK business school. The module's assessment was based on a group simulation game performance and a final exam. The SG adopted for this module was the GLO-BUS SG developed by GLO-BUS Software Inc. GLOBUS, since its introduction in 2004, has been used by more than 1,620 instructors involving over 240,000 students at 715 universities in 51 countries (GLO-BUS).

In GLO-BUS, students are distributed into groups where 4-6 students are assigned to run a digital camera company. The company produces and markets entry-level and upscale, multi-featured cameras in head-to-head competition in a global market arena against companies run by other members of the class. Students take the roles of company comanagers to determine the quality and performance features of the cameras to be produced. The students impact production costs by raising/lowering camera quality and performance, adjusting work force compensation, spending more/less on worker training, lengthening/shortening warranties offered, and by how efficiently they manage the camera assembly process. For ten weeks, students were involved in collaborative learning teams to make decisions in this competitive environment, trying to meet investors' expectations as outlined by the game rules.

All cause-effect relationships and underlying algorithms in GLO-BUS are based on business and economic principles and connect closely to the real-world digital camera 
industry. This allows students to think logically as they analyse industry and company conditions. The game provides students with an authentic learning experience, a means of building skills in analysing markets and competitors, a true experience to practise decisionmaking, and a venue to apply knowledge gained in business school (GLO-BUS).

\section{Instruments and Procedures for Data Collection}

For the quantitative research method, a self-administered questionnaire was distributed during the final module lectures to students who were informed about the purpose of the survey and assured of anonymity and confidentiality. The questionnaire explores students' perceptions of the game and evaluations of their experience of using the SG. Participants were asked to indicate their level of agreement or disagreement with statements relating to their experiences of playing the game. Each item was scored on a five-point Likert scale ranging from strongly disagree (1) to strongly agree (5). Items were adopted from scales developed by (Ranchhod et al., 2014) to measure students' experience generation, conceptual understanding, skills development, and affective evaluation respectively. The rest of the questions were designed to investigate students' perception of the game, the assigned tasks they had to perform, and how the administration of the game could be improved.

For the qualitative research method, after finishing the SG students were asked to reflect on their experience and provide written feedback in a reflective report being part of an assessment component for the module. The reflective report is considered a more in-depth qualitative approach that can provide valuable insights into students' learning experience (Wills \& Clerkin, 2009). Students were informed that the reflective report will be used for analysis as part of this research and the enhancement of the SG experience. The reflective report encouraged students to express their thoughts, feelings and analyses of what they had learned and experienced in the game. The aim was to gain understanding on what students 
had learned in the game and how this learning affected their decisions in the game and in their future practices. As argued by Gibbs, Rust, Jenkins, and Jaques (1994, p. 9) "It is not sufficient simply to have an experience in order to learn. Without reflecting upon this experience, it may quickly be forgotten, or its learning potential lost. It is from the feelings and thoughts emerging from this reflection that generalisations or concepts can be generated". Indeed, through this process the study gathered a vast amount of qualitative data with rich narratives and commentary. Thus, the reflective reports demonstrate how the game enabled students to develop their problem solving and decision-making skills and apply concepts and theories.

\section{Analysis and Findings}

\section{The Quantitative Study}

Findings represented in this section are based on statistical analysis of the questionnaire data using SPSS. Out of 155 students enrolled in the module over three years, 120 completed the post-game evaluation questionnaire ( $51 \%$ male, $49 \%$ female). The average age of the participating students was 25 years. Exploratory factor analysis and reliability analysis were performed to assess the constructs' measurement. Reliability is estimated via internal consistency and Cronbach's alpha, and validity is estimated with factor analysis and intercorrelation between constructs (Churchill, 1979). Cronbach's alphas for each construct were greater than 0.70 indicating acceptable reliability (Nunnally, 1978). Item factor loadings, means, standard deviations along with reliability and AVE scores for each construct are reported in Table 1.

Insert Table 1 about here 
Regression analysis results support hypotheses 1, 2, and 3 (Table 2): SG generated experience has a positive impact on conceptual understanding, skills development and affective evaluation.

Insert Table 2 about here

This study also suggests that conceptual understanding and skills development mediate the effect of experience generation on affective evaluation. The mediation effect was tested by using criteria recommended by Baron and Kenny (1986), regression analyses were performed to test hypotheses 4 and 5 (Table 3). Findings indicate that no full mediation effect was found, hence rejecting hypotheses 4 and 5. Figure 1 presents the study's conceptual model and findings.

Insert Table 3 about here

Insert Figure 1 about here

\section{The Qualitative Study}

Qualitative data analysis started with familiarisation and immersion in the data (Miles \& Huberman, 1994) by thoroughly reading through the content of the reflective reports, a process which produced meaningful insight into the students' experience of playing the SG. 
At the same time, themes and expressions used by students to communicate their reflections on the experience were identified.

Content analysis was performed with NVivo 11 to identify themes in the data in line with the process of theme and content analysis (Miles \& Huberman, 1994). The coding process started with intensive and repeated reading of the content to identify word(s) that conceptually belong to or represent what the researchers believe is the meaning of that data (Miles \& Huberman, 1994).

This study employed two coding strategies: a priori and a posteriori categorisation of data. A priori coding refers to the use of theory and literature to develop categories. A posteriori coding involves developing categories based on the data (Sinkovics, Penz, \& Ghauri, 2008). Following a priori coding strategy, the constructs of the conceptual model guided the coding and analysis of qualitative data. The aim was to find out if the educational values hypothesised in the conceptual model were evident in the students' feedback descriptions. Table 5 highlights the themes emerged from students' reflective reports along with representative quotations, confirming the value generation model identified in the quantitative research.

The posteriori coding strategy yielded insights about themes emerged from students' narratives and included: game complexity, adaptability, information overload, teamwork challenges, dealing with disappointing results, and the game not fully representing reality.

Insert Table 4 about here

\section{Discussion and Conclusion}

Game-based learning literature suggests that it is critical to focus on a learner's experience for any analysis of the effectiveness of a game-based learning experiment (Chin, 
Dukes, \& Gamson, 2009; Lovelace et al., 2016). Therefore, this study uses a mixed-method approach to enhance the quality and robustness of the research on students' perspectives of educational values generated by using a SG. This research empirically validated four types of educational value generated by the GLO-BUS simulation game: experience learning, conceptual understanding, professional skills development, and affective evaluation (Table 2). The qualitative approach adopted by this study further supported the quantitative results and gave deeper insight into the complex factors that lead to learning in a SG exercise (Table 4).

Results indicate that the game gave students the chance to experiment with different ideas and to gain valuable experience by implementing strategic decisions (experiential value). Students confirmed that the SG offered an opportunity of a rich and exciting experience within an engaging learning environment. The finding supports the argument that strategybased games are effective tools for developing students' conceptual understanding (Lovelace et al., 2016).

EL theory advocates that the iterative EL process enables learners to develop skills such as critical thinking attained from experimentation, feedback on performance, and opportunity for reflection (Kolb, 1984). In this study, students highlighted that participating in the game developed their skills in data analysis, strategic decision making, problem solving and teamwork. The findings support (Salas et al., 2009) suggestions that SG accelerate the development of management and decision making skills because of the games' ability to collapse time and space and provide ample opportunities for experience development.

The findings confirm the affective evaluation of the use of the SG in enhancing the students' experience. The competitive dynamics of the game increased students' engagement and motivation to learn. Our research demonstrates the merit of the SG as a powerful learning experience which stimulates positive energy and classroom excitement, engages students, 
promotes effective learning by doing, and helps develop students' critical thinking skills (Lovelace et al., 2016).

This study contributes to EL and game-based learning literature by providing empirical evidence from learners' perspectives about the educational values generated from the use of a simulation game. There are many obstacles preventing academics from adopting simulation as a teaching method. These obstacles include: preparation time, lack of relevance to curriculum, lack of sufficient information about well-designed games, preference for alternative pedagogical methods, funding, administrative and technical issues (Faria \& Wellington, 2004). By providing empirical evidence, this study confirms how a welldesigned simulation game can enhance management students' learning experience.

Given the educational values generated from a well-designed simulation game, this study recommends that educators should embrace the learning and skills development opportunities SG provide. When embedding SG in management curriculum, educators should be guided by the attributes of experience generation, conceptual understanding, skills development and affective evaluation identified in this study. It is necessary that faculties makes resources available to academics to experiment with SG in line with module objectives to enhance students' learning and skills development, thereby increasing students employment prospects (Salas et al., 2009)

In this digital age, students value a digital learning environment in which they can access, share, and manipulate data anywhere (Daspit \& D'Souza, 2012; Proserpio \& Gioia, 2007). Therefore, one of the challenges facing management educators is to find ways to use new technology-blended learning approaches to teach the virtual generation (Daspit \& D'Souza, 2012). This study provides evidence on students' positive learning experience from the blending of SG into the teaching of the module. 
Based on the three years' experience of administration of the game, some key successful factors were identified. These relate to providing students with practice rounds and advice for corrective actions, explaining how theories should guide decisions-making in the game, allowing self and peer evaluations to be included in students' performance assessment, and encouraging reflective analysis. Allocating time for debriefing the results after each decision round is paramount to ensure students are aware of the consequences of their strategic decisions.

There are limitations to this study that should be considered when interpreting the findings. While the findings suggest that students perceived the SG as an effective approach to learning, the study was limited to a single module setting. This suggests that this research needs to be applied in different institutions or using different SG to generalise the findings. The study relied on student feedback data. For future research, more evidence is needed to validate the educational values generated from other well-crafted SG by incorporating data from different sources (assessment of performance, attainment of learning outcomes, instructors' observation). Further research can conduct a longitudinal study to explore whether the experience of playing SG makes students better business decision makers.

\section{Conclusion}

This study contributes to the literature on game-based learning and EL through the empirical evaluation of the educational value of using SG, from the students' perspective. The underlying premise of this study is consistent with the view that EL has a positive impact on students' engagement and learning. This study acknowledges that game-based learning requires students and instructors to fully engage with the game to understand the dynamics and challenges emerging from all the decisions made in the game. Administrating a SG requires investing more time to keep up-to-date with teams' performance to provide valuable advice. Therefore, the instructor's interest and commitment in guiding students through their 
learning experiments is a critical factor in providing positive game-based learning. Adopting the simulation game proved to be very effective from both the students' and the researchers' perspective. Finally, it is hoped that this research inspires more management educators to consider adopting SG to enhance students' learning experiences. 


\section{REFERENCES}

Baron, R. M., \& Kenny, D. A. (1986). The moderator-mediator variable distinction in social psychological research: Conceptual, strategic, and statistical considerations. Journal of Personality and Social Psychology, 51(6), 1173.

Blood, M. R. (2006). Only You Can Create Actionable Knowledge. Academy of Management Learning \& Education, 5(2), 209-212. doi:10.5465/AMLE.2006.21253786

Bower, J. L. (2008). The Teaching of Strategy. Journal of Management Inquiry, 17(4), 269275.

Chin, J., Dukes, R., \& Gamson, W. (2009). Assessment in Simulation and Gaming: A Review of the Last 40 Years. Simulation \& Gaming, 40(4), 553-568. doi:10.1177/1046878109332955

Churchill, G. A. (1979). A Paradigm For Developing Better Measures Of Marketing Constructs. Journal of Marketing Research, 16, 64-73.

Creswell, J. (2009). Research design: Qualitative, quantitative, and mixed methods approaches: SAGE Publications, Incorporated.

Daspit, J. J., \& D'Souza, E. E. (2012). Using the Community of Inquiry Framework to Introduce Wiki Environments in Blended-Learning Pedagogies: Evidence From a Business Capstone Course. Academy of Management Learning \& Education, 11(4), 666-683. doi:10.5465/amle.2010.0154

Faria, A. J., \& Wellington, W. J. (2004). A survey of simulation game users, former-users, and never-users. Simulation \& Gaming, 35(2), 178-207. doi:10.11 77/10468781/263543

Gibbs, G., Rust, C., Jenkins, A., \& Jaques, D. (1994). Developing Students' Transferable Skills: Oxford Centre for Staff Development.

GLO-BUS. Developing Winning Competitive Strategies, A strategy simulation created by Arthur A. Thompson, Gregory J. Stappenbeck, et al., accessed at www.glo-bus.com, marketed by McGraw-Hill Education.

Gosen, J., \& Washbush, J. (2004). A Review of Scholarship on Assessing Experiential Learning Effectiveness. Simulation \& Gaming, 35(2), 270-293. doi:10.1177/1046878104263544

Greiner, L. E., Bhambri, A., \& Cummings, T. G. (2003). Searching for a Strategy to Teach Strategy. Academy of Management Learning \& Education, 2(4), 402-420. doi:10.5465/AMLE.2003.11902092

Jarzabkowski, P., Giulietti, M., Oliveira, B., \& Amoo, N. (2013). “We Don't Need No Education"-Or Do We? Management Education and Alumni Adoption of Strategy Tools. Journal of Management Inquiry, 22(1), 4-24. doi:10.1177/1056492612460588

Kauneckis, D. L., \& Auer, M. R. (2013). A Simulation of International Climate Regime Formation. Simulation \& Gaming, 44(2/3), 302-327. doi:10.1177/1046878112470542

Kolb, A. Y., \& Kolb, D. A. (2005). Learning styles and learning spaces: Enhancing experiential learning in higher education (Vol. 4, pp. 193-212).

Kolb, A. Y., \& Kolb, D. A. (2009). The Learning Way: Meta-cognitive Aspects of Experiential Learning. Simulation \& Gaming, 40(3), 297-327. doi:10.1177/1046878108325713

Kolb, D. (1984). Experiential learning: Experience as a source of learning and development. Upper Saddle River, NJ: Prentice Hall.

Leemkuil, H., \& De Jong, T. O. N. (2012). Adaptive Advice in Learning With a ComputerBased Knowledge Management Simulation Game. Academy of Management Learning \& Education, 11(4), 653-665. doi:10.5465/amle.2010.0141

Lovelace, K. J., Eggers, F., \& Dyck, L. R. (2016). I Do and I Understand: Assessing the Utility of Web-Based Management Simulations to Develop Critical Thinking Skills. 
Academy of Management Learning \& Education, 15(1), 100-121. doi:10.5465/amle.2013.0203

Miles, M. B., \& Huberman, A. M. (1994). Qualitative Data Analysis: An Expanded Sourcebook. London: Sage.

Nunnally, J. C. (1978). Psychometric Theory: New York: McGraw-Hill Book Company.

Pfeffer, J., \& Fong, C. T. (2002). The end of business schools? Less success than meets the eye. Academy of Management Learning \& Education, 1(1), 78-95.

Proserpio, L., \& Gioia, D. A. (2007). Teaching the Virtual Generation. Academy of Management Learning \& Education, 6(1), 69-80. doi:10.5465/AMLE.2007.24401703

Ranchhod, A., Gurău, C., Loukis, E., \& Trivedi, R. (2014). Evaluating the educational effectiveness of simulation games: A value generation model. Information Sciences, 264, 75-90. doi:10.1016/j.ins.2013.09.008

Salas, E., Wildman, J. L., \& Piccolo, R. F. (2009). Using Simulation-Based Training to Enhance Management Education. Academy of Management Learning \& Education, 8(4), 559-573. doi:10.5465/amle.2009.47785474

Sinkovics, R., Penz, E., \& Ghauri, P. (2008). Enhancing the trustworthiness of interview based qualitative research. Management International Review, 6, 689-714.

Wellington, W. J., \& Faria, A. J. (1996). The Use of Simulation Games in Marketing Classes: Is Simulation Performance Due to Luck or Skill? Journal of Marketing Education, 18(2), 50-61.

Wills, K. V., \& Clerkin, T. A. (2009). Incorporating Reflective Practice Into Team Simulation Projects For Improved Learning Outcomes. Business Communication Quarterly, 72(2), 221-227.

Wolfe, J., \& Roberts, C. R. (1993). A Further Study of the External Validity of Business Games: Five-Year Peer Group Indicators. Simulation \& Gaming, 24(1), 21-33. doi:10.1177/1046878193241004

Zantow, K., Knowlton, D. S., \& Sharp, D. C. (2005). More Than Fun and Games: Reconsidering the Virtues of Strategic Management Simulations. Academy of Management Learning \& Education, 4(4), 451-458. doi:10.5465/AMLE.2005.19086786 
TABLE 1: Constructs' Measurement

\begin{tabular}{|c|c|c|c|c|}
\hline Factors & Items & FL & Mean & SD \\
\hline \multirow{4}{*}{$\begin{array}{l}\begin{array}{l}\text { Experience } \\
\text { generation } \\
(\alpha=0.73 ; \\
\text { AVE }=0.66)\end{array}\end{array}$} & Glo-Bus gave me the opportunity to: & & & \\
\hline & take risks I could not take in a real business & .767 & 4.1 & 0.7 \\
\hline & experiment with different business ideas & .806 & 4.4 & 0.6 \\
\hline & have strategic perspective & .868 & 4.4 & 0.6 \\
\hline \multirow{8}{*}{$\begin{array}{l}\text { Conceptual } \\
\text { Understanding } \\
(\alpha=0.88 ; \\
\text { AVE }=0.60)\end{array}$} & Playing Glo-Bus enabled me to better understand: & & & \\
\hline & product designing strategy & .810 & 4.0 & 0.5 \\
\hline & pricing strategy & .765 & 4.3 & 0.6 \\
\hline & distribution strategy & .791 & 4.0 & 0.6 \\
\hline & advertising and promotion strategy & .869 & 4.1 & 0.7 \\
\hline & human resource management & .710 & 3.7 & 0.8 \\
\hline & financial performance & .769 & 4.0 & 0.7 \\
\hline & international marketing strategy & .697 & 4.2 & 0.7 \\
\hline \multirow{11}{*}{$\begin{array}{l}\text { Skills } \\
\text { Development } \\
(\alpha=0.87 ; \\
\text { AVE }=0.48)\end{array}$} & Glo-Bus enabled me to: & & & \\
\hline & feel working in a realistic environment & .764 & 3.8 & 0.9 \\
\hline & evaluate the success of particular strategies that were adopted & .763 & 4.0 & 0.7 \\
\hline & learn issues that they would not normally have picked up in a class situation & .775 & 4.1 & 0.7 \\
\hline & recognise the difference between tactics and strategies & .687 & 4.0 & 0.8 \\
\hline & analyse information more effectively & .527 & 4.0 & 0.6 \\
\hline & work more effectively in groups & .618 & 4.1 & 0.6 \\
\hline & critically evaluate firm's strategy & .663 & 4.0 & 0.7 \\
\hline & use information more effectively & .839 & 4.0 & 0.6 \\
\hline & use the skills gained in other parts of the module & .547 & 4.0 & 0.7 \\
\hline & use the learned skills in future jobs & .684 & 4.0 & 0.7 \\
\hline \multirow{6}{*}{$\begin{array}{l}\begin{array}{l}\text { Affective } \\
\text { evaluation } \\
(\alpha=0.84 ; \\
\text { AVE }=0.61)\end{array}\end{array}$} & The Glo-Bus SG & & & \\
\hline & Motivated me to want to succeed in the simulation & .839 & 4.3 & 0.7 \\
\hline & Motivated me to learn about business/marketing strategies & .776 & 4.3 & 0.6 \\
\hline & I find this type of experience conducive to learning effectively & .808 & 4.3 & 0.6 \\
\hline & I find a competitive environment helpful in learning business issues & .719 & 4.3 & 0.7 \\
\hline & This type of learning requires total involvement in the exercise & .744 & 4.4 & 0.6 \\
\hline
\end{tabular}

$\alpha=$ Cronbach's Alpha; $\boldsymbol{A} \boldsymbol{V} \boldsymbol{E}=$ Average Variance Extracted 
TABLE 2: Regression Analysis

\begin{tabular}{lccc}
\hline & \multicolumn{3}{c}{ Dependent Variables } \\
\hline $\begin{array}{l}\text { Conceptual } \\
\text { Understanding }\end{array}$ & $\begin{array}{c}\text { Skills } \\
\text { Development }\end{array}$ & $\begin{array}{c}\text { Affective } \\
\text { Evaluation }\end{array}$ \\
$\begin{array}{l}\text { Experience Generation } \\
\text { Control variables }\end{array}$ & $.48^{* *}(5.7)$ & $.55^{* *}(7.1)$ & $.48^{* *}(5.8)$ \\
Age & & & \\
Gender & $.059(.715)$ & $.113(1.5)$ & $.043(.57)$ \\
$\mathrm{R}^{2}$ & $.011(.138)$ & $.009(12)$ & $.016(.22)$ \\
$\mathrm{F}$ & .24 & .34 & .38 \\
\hline
\end{tabular}

$\mathrm{B}=$ Standardised Coefficients. $* * \mathrm{p}<0.01$ (t-values) 


\begin{tabular}{lcc}
\hline & \multicolumn{2}{c}{ Affective Evaluation } \\
\hline $\begin{array}{l}\text { Independent Variables } \\
\text { Experience generation }\end{array}$ & $\begin{array}{c}\text { Model 1 } \\
\text { Experience generation }+ \\
\text { Conceptual understanding }\end{array}$ & $\begin{array}{c}\text { Experience generation + Skills } \\
\text { development }\end{array}$ \\
$\begin{array}{l}\text { Conceptual understanding } \\
\text { Skills development }\end{array}$ & $.49 * *(5.6)$ & $.25 * *(3.296)$ \\
Control variables & $.17 *(2.0)$ & $.58^{* *}(7.5)$ \\
Age & & \\
Gender & $.04(.519)$ & $.028(44)$ \\
$\mathrm{R}^{2}$ & $.025(.326)$ & $0.28(.44)$ \\
$\mathrm{F}$ & .36 & .56 \\
\hline $\mathrm{B}=$ Standardised Coefficients. $* * \mathrm{p}<0.01(\mathrm{t}-\mathrm{values})$ & $35.99 * *$ \\
\hline
\end{tabular}

$\mathrm{B}=$ Standardised Coefficients. $* * \mathrm{p}<0.01$ ( $\mathrm{t}$-values) 
TABLE 4: Educational Values Generated by the Game

\begin{tabular}{ll}
\hline Constructs & Sample of students' comments \\
\hline Experience generation & "A valuable opportunity to experience a real-world business environment with \\
& applied learning...integrates cumulative knowledge from all of the management \\
courses and lectures I attended". & "A good experience...gave us an opportunity to learn something new ...made us \\
more informative about business and I was able to relate theory to the real \\
business". \\
"The simulation is the most exciting part of the module, it helped us to combine the \\
theoretical and practice together". \\
"...the depth of leadership lessons and skills that I have learnt during this \\
process...this exercise has made a positive impact on me as an individual and as a \\
young professional. I consider this a litmus test for being an effective manager in a \\
real-world corporation." \\
"A high quality intellectual stretching exercise with a plethora of factors that \\
influences critical thinking, sound decision making for all participants". \\
"The simulation game has been one of my most enjoyable courses and I am \\
disappointed that the game has come to an end, it has been a wonderful learning \\
experience for both me and my team." \\
"This was a pretty entertaining experience and the way it was introduced and \\
executed was really enjoyable".
\end{tabular}

Note: Students' grammar not corrected. 
FIGURE 1: Conceptual Model

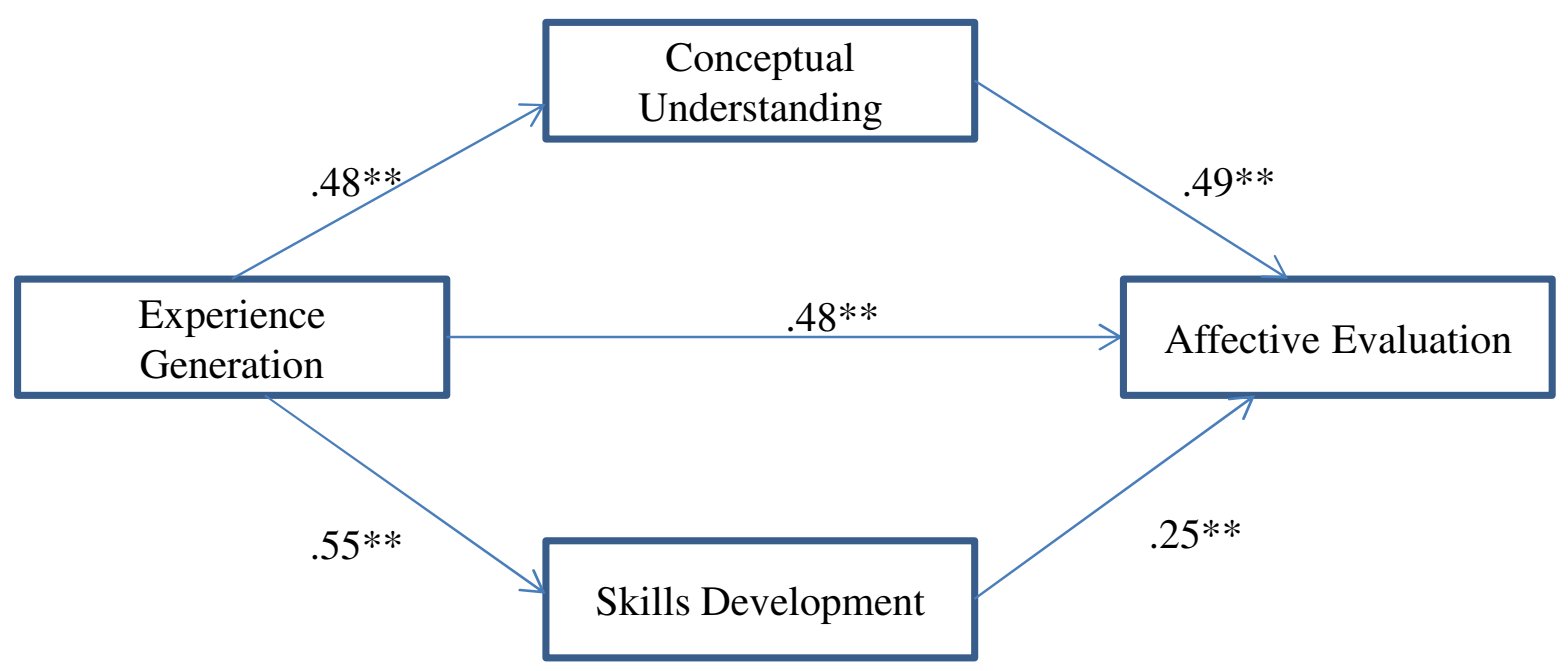

Note: $* *=p<.01$ 